\title{
Use of social media platforms for improving academic performance at Further Education and Training colleges
}

\begin{tabular}{|c|c|}
\hline \multicolumn{2}{|c|}{$\begin{array}{l}\text { Authors: } \\
\text { Godwin P. Dzvapatsva }{ }^{1} \\
\text { Zoran Mitrovic }{ }^{1} \\
\text { Anthony D. Dietrich }{ }^{1}\end{array}$} \\
\hline \multicolumn{2}{|c|}{$\begin{array}{l}\text { Affiliation: } \\
{ }^{1} \text { Department of Information } \\
\text { Systems, University of the } \\
\text { Western Cape, South Africa }\end{array}$} \\
\hline \multicolumn{2}{|c|}{$\begin{array}{l}\text { Correspondence to: } \\
\text { Godwin Dzvapatsva }\end{array}$} \\
\hline \multicolumn{2}{|c|}{$\begin{array}{l}\text { Email: } \\
\text { gpdzvapatsva@yahoo.com }\end{array}$} \\
\hline \multicolumn{2}{|c|}{$\begin{array}{l}\text { Postal address: } \\
2 \text { Gabriel Road, Plumstead } \\
7800 \text {, Cape Town, } \\
\text { South Africa }\end{array}$} \\
\hline \multicolumn{2}{|c|}{$\begin{array}{l}\text { Dates: } \\
\text { Received: } 03 \text { Dec. } 2013 \\
\text { Accepted: } 07 \text { Sept. } 2014 \\
\text { Published: } 17 \text { Nov. } 2014\end{array}$} \\
\hline \multicolumn{2}{|c|}{$\begin{array}{l}\text { How to cite this article: } \\
\text { Dzvapatsva, G.P., Mitrovic, Z. } \\
\text { \& Dietrich, A.D., 2014, 'Use } \\
\text { of social media platforms } \\
\text { for improving academic } \\
\text { performance at Further } \\
\text { Education and Training } \\
\text { colleges', South African } \\
\text { Journal of Information } \\
\text { Management } 16(1) \text {, Art. } \\
\text { \#604, } 7 \text { pages. http://dx.doi. } \\
\text { org/10.4102/sajim.v16i1.604 }\end{array}$} \\
\hline \multicolumn{2}{|c|}{$\begin{array}{l}\text { Copyright: } \\
\text { (C) 2014. The Authors. } \\
\text { Licensee: AOSIS } \\
\text { OpenJournals. This work } \\
\text { is licensed under the } \\
\text { Creative Commons } \\
\text { Attribution License. }\end{array}$} \\
\hline \multicolumn{2}{|c|}{ Read online: } \\
\hline 口ididn & $\begin{array}{l}\text { Scan this QR } \\
\text { code with your } \\
\text { smart phone or } \\
\text { mobile device } \\
\text { to read online. }\end{array}$ \\
\hline
\end{tabular}

\section{Authors:}

Zoran Mitrovic

Anthony D. Dietrich

Systems, University of the

Correspondence to:

Email:

Postal address:

2 Gabriel Road, Plumstea

7800, Cape Town

Dates:

Accepted: 07 Sept. 2014

How to cite this article: vapatsva, G.P., Mitrovic, Z. of social media platforms for improving academic performance at Further Education and Training \#604, 7 pages. http://dx.doi.

Copyright:

is licensed under the

Creative Common

Attribution License.

\begin{abstract}
Background: The National Certificate Vocational (NC[V]) curriculum offered by Further Education and Training (FET) colleges was introduced in 2007 to address the skills shortage in South Africa. Information Technology (IT) lecturers encountered a number of challenges in delivering lessons throughout the course, which affected the academic performance of learners. The biggest challenges identified were the lack of adequate contact hours for the course and inconsistency in the way in which final examination papers were set.
\end{abstract}

Objectives: The aim of the project was to investigate the use of: (1) a knowledge portal for verifying the quality of assessments by lecturers and (2) social media to increase contact time with FET college students in an attempt to improve their academic performance.

Method: The NC(V) level 3 student test scores for 2011 were compared to those of 2012. In addition to the test scores, students also received a questionnaire so as to determine their perceptions on social media usage. Lecturers also received a questionnaire on their perception of the knowledge portal.

Results: The data collected from seven lecturers and 38 students indicated a 35\% (from 30\% $65 \%$ ) improvement in academic performance after the introduction of the interventions, that is social media and a knowledge portal; an indication of the importance of electronic media in enhancing learning.

Conclusion: The research offered FET lecturers an additional method for learning and teaching in that they could use the knowledge portal to set up quality assessments for the students and social media to increase contact learning time.

\section{Introduction}

The skills shortage in South Africa has seen the government making frantic efforts to address the problem through Further Education and Training (FET) colleges. One such initiative was the National Certificate Vocational (NC[V]) curriculum, which was introduced in 2007. The target population for the $\mathrm{NC}(\mathrm{V})$ curriculum is learners who passed Grade 9 . As reflected by the low pass rate of 2011 and preceding years, this curriculum is however proving to be challenging to most of the students. It remains the task of the lecturer to come up with innovative ways to ensure that students perform well. This study suggests the use of social media (SM) by students and a knowledge portal (KP) for assessments by lecturers to improve academic efficiency. The two suggested solutions, SM and a KP, have been found in separate studies to be vital in the sharing of knowledge between students and lecturers (Dietrich, Whyte \& Mitrovic 2011; Dzvapatsva 2013; Koles \& Nagy 2012). All the knowledge generated from previous lecturers and other sources, for example departmental sample papers, is stored and transferred to other lecturers through the KP for assessments. The students are encouraged to use the Facebook (FB) group created by lecturers to increase contact time outside normal learning time.

It is presumed that most of the senior staff at the FET colleges grasp the need to share knowledge with the junior staff so as to increase or enhance learning; thus, they 'are eager to introduce knowledge management paradigms' (Bock \& Kim 2002). From the literature (Koles \& Nagy 2012) it appears that SM platforms have a remarkable effect on learning.

The use of electronic platforms, especially SM, for the purpose of knowledge sharing amongst FET students has been criticised by various researchers (Hamid, Chang \& Kurnia 2009; Sarachan \& Reinson 2011). A random sample of lecturers at a South African FET college indicated that most of the students from non-IT departments were against the idea of using electronic platforms, 
especially SM, for the purpose of knowledge dissemination amongst students and lecturers. These lecturers argued that electronic platforms like FB are disruptive and destructive. However, other researchers (Kabilan, Ahmad \& Abidin 2010) found the opposite to be true. They argued that SM platforms like FB could bring positive results in academic performance, if well administered. This is why the authors of this article decided to use FB to increase the contact time required for the subject by the students and the $\mathrm{KP}$ for knowledge sharing amongst lecturers. It was the view of these researchers (Dzvapatsva 2013; Dietrich et al. 2011) that $\mathrm{NC}(\mathrm{V})$ was heavily congested in terms of the time needed for the subject and students were left with not enough time to study or to do research whilst at the college (Leung 2002). Owing to the geographical distance, students could be contacted via SM platforms, like FB, which could accessed by most students from any location.

Apart from the students, the lecturers do not have enough time to do research or examine the subject content from previous lecturers or fellow subject experts. The KP seems to be the best electronic source which lecturers can use as reference for work done by previous and current subject experts. At the same time, FB seems to offer an alternative in capturing students' attention outside the classroom to review what they have learnt or will learn in the following lecture.

\section{Background}

The $\mathrm{NC}(\mathrm{V})$ programme was introduced to FET colleges in 2007 in an effort to redress the skills imbalance in South Africa. All learners who wanted to proceed with their studies along a chosen career path, for example Information Technology (IT), Business Administration, Engineering, Marketing or Tourism, could opt for the $\mathrm{NC}(\mathrm{V})$ programme. The NC(V) programme draws its students from Grade 9-12. The entry qualification is a pass in Grade 9, or the student must be older than 16 years. It runs for a period of three years, thus level 2 to level 4 . Each year is an exit point. At each level a student is expected to successfully complete seven subjects, which comprise four core subjects, two fundamental ones, and one elective. Most students, however, struggle to pass all seven subjects so as to be promoted to the next level. The promotional policy allows students with a pass in five subjects to proceed to the next level. Lecturers have to work extremely hard and implement measures to improve students' performance so that FET colleges remain economically viable; these measures include the use of electronic platforms. In the event that a student is promoted to the next level whilst requiring one or two subjects for the previous level, he or she will have to do seven subjects of the present level and two extra subjects, which becomes stressful for the student. In view of the aforementioned, lecturers had to design means to assist students and to improve academic efficiency at each level, hence the introduction of electronic platforms. At the South African FET colleges used for this study, the SM platform, Facebook, has been used to contact learners outside the normal teaching time to increase contact hours for the Programming component, which has been identified as one of the challenging subjects. The lecturers also used a portal for the setting up of assessments, subject notes, tests, and worked-out solutions. This has presumably been suggested to assist in drastically reducing the bottleneck and directly improve the throughput rate of students at FET colleges, which ultimately will contribute towards overall academic fulfilment (Dzvapatsva 2013). Studies by researchers, including Kabilan et al. (2010), has shown the positive use of SM for academic improvement, ultimately improving the throughput rate. In parallel, researchers like Rajalakshmi and WahidiBanu (2009) identified the KP application as a possible solution to academic inefficiency.

\section{Literature review}

It should be noted that whilst the traditional medium of face-to-face interaction offers numerous advantages for teaching and learning, it is controlled by time and space. In that respect it becomes crucial to embrace new technologies to supplement the current traditional ones in the teaching and learning of college and university students. With electronic media, the world becomes the classroom, available 24/7, and not confined to Mondays to Fridays.

According to Kaplan and Haenlein (2010), SM is defined as 'a group of Internet-based applications that build on the ideological and technological foundations of Web 2.0, and that allow the creation and exchange of User Generated Content'. The two main aspects discussed here are media research and social processes. Each medium used by the lecturer differs in its degree of effectiveness, depending on whether it is visual, acoustic or physical (Short, Williams \& Christie 1976). Taking this into consideration, the current generation of students are more visual, hence the use of FB. It should also be considered that these students are a product of Outcome Based Education (OBE), which requires them to demonstrate the skills and subject content that they are expected to learn, regardless of whether they are comfortable with the medium used. Students prefer a medium which increases self-disclosure and selfpresentation, thereby increasing social influence. The more a medium reduces ambiguity and uncertainty, the more it is accepted by communicating students (Daft \& Lengel 1986).

Generally, SM encompasses the following:

- social networking sites (SNS), such as Facebook, Twitter, MySpace and LinkedIn

- media sharing sites, such as YouTube, Flickr and Tumbler

- wikis and blogs

- syndication of content through Rich Site Summary (RSS) feeds

- republishing tools (Gikas \& Grant 2013).

According to Greenhow (2011, cited in Gikas \& Grand 2013), SM 'tools in learning promotes a more studentcentred course'. SM allows learners to network and work in partnership with each other and instructors. 
Barczyk and Duncan (2011) identified elements that shape how Web 2.0 tools can be used meaningfully. Without structure, SM can negatively impact student learning. According to Barczyk and Duncan (2011), SM is used for educational purposes by lecturers at colleges and universities for learning and teaching. Studies by Barczyk and Duncan (2011) also indicated that more than half of the surveyed professors used tools such as videos, blogs, podcasts, video casts, and wikis in their classes. In his framework of SM, Kietzmann et al. (2011) identified seven building blocks for its functionality and usage: identity, conversation, sharing, presence, relationship, reputation and groups (Rosmalab \& Rosmalab 2012). The diagram in Figure 1 illustrates the SM functionality framework.

$\mathrm{SM}$ is not new in the learning and teaching sector, but it is still not widely accepted. It is important to note that if, and only if, the medium is used for educational purposes and following set regulations by students to supplement the existing medium, a positive result will be obtained within the FET sector (Dzvapatsva 2013). Dzvapatsva (2013) states that students with certain personality types, who might have proved to be difficult to engage, can benefit more from the use of electronic media.

For example, 'shy students' proved to have benefited more online than they had done through face-to-face interaction with the lecturer (Dzvapatsva 2013). However, the electronic medium should be used to supplement the already existing methods or mediums, and should not be a complete replacement. SM helps learners to collaborate and interact with each other, which are key aspects in higher education. Furthermore, SM facilitates informal learning (Ebner et al. 2010). Informal learning is described

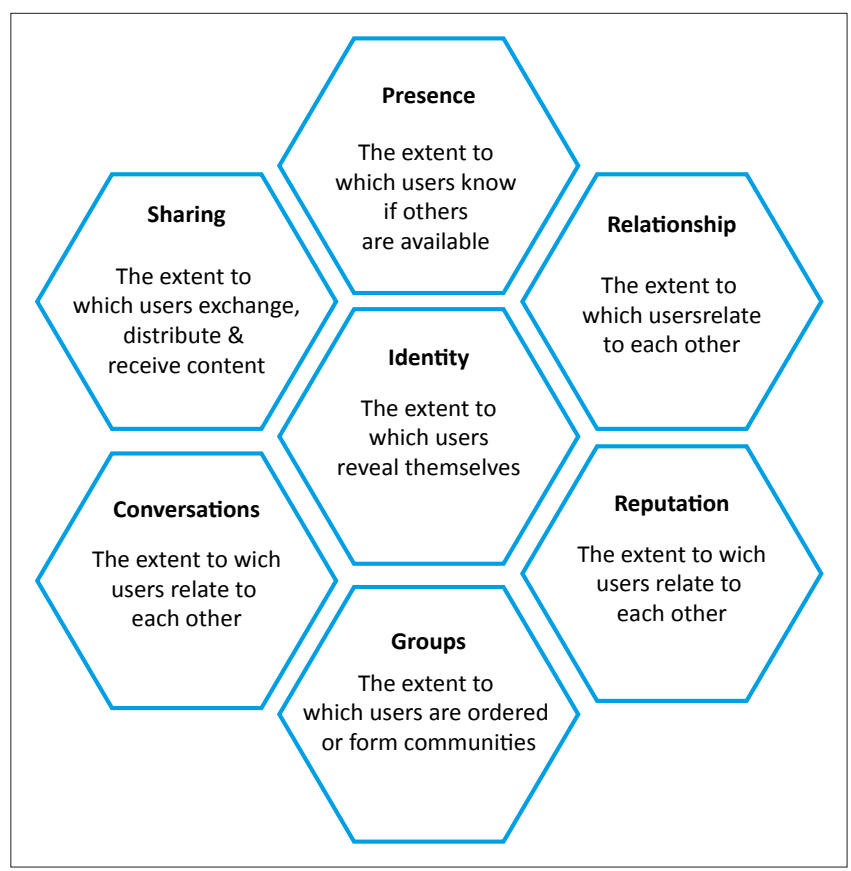

Source: Adapted from Kietzmann, J.H., Hermkens, K., McCarthy, I.P. \& Silvestre, B.S. 2011 , 'Social media? Get serious! Understanding the functional building blocks of social media', Business Horizons 54, 241-251

FIGURE 1: Social media functionality framework. as contextualised, unorganised, but intentional (Gikas \& Grant 2013). Mobile computing, which is an extension of electronic learning through mobile devices, can be used to do research, investigate, collect information and collaborate with other students through social networking sites (SNS). The information gathered will be used to supplement formal learning (Gikas \& Grand 2013). Electronic platforms like SM and a KP allow students to access study material and communicate with classmates and instructors, no matter where they are (Gikas \& Grand 2013). In addition, electronic platforms allow students to classify, control and evaluate existing knowledge, and successfully put together and communicate this as new knowledge.

Within the higher education sector, especially at FET colleges in South Africa, an information technology subject is found in most courses, either as Life Orientation (LO) or as Office Data Processing (ODP). These subjects focus on familiarising students with technology. Furthermore, they developing the academic skills required to locate specialised information, as well as for managing data, conducting online research, creating and managing documents and internet usage software. Lecturers in the field of Information Communication and Technology (ICT) should be aware of the fact that electronic technologies have transformed learning styles as most students would been using SM, for example FB, Twitter and Whatsapp, for a few years already, mainly by means of electronic devices, and lately, mobile devices.

\section{Social media challenges within the FET sector}

E-learning platforms like SM and KPs offer many advantages when compared to the traditional chalk-and-board methods. Some of the possible advantages, as noted by Cantoni, Cellario and Porta (2004), include:

- less expensive to deliver and faster

- provides consistent content, unlike in traditional methods where different lecturers can teach the same content differently

- it works from anywhere and anytime (virtual classroom)

- it can improve retention through varying types of content through videos and interaction

- it provides immediate feedback, especially if mobile devices are being used

- students are not afraid to make mistakes online so they can take risks and that alone can have a lasting positive effect (n.p.).

E-learning platforms are different from classroom-based learning; hence they require accurate development, monitoring and management. Electronic platforms, such as portals, require real subject experts to generate new skills in content and to verify the existing knowledge. It requires lecturers to be cognitively sensitive and well-sequenced. It also requires the explicit selection of instructional design to make learning experiences effective and long-lasting (Cantoni et al. 2004). Cantoni et al. (2004:336) state that electronic platforms may be 'intimidating, confusing or 
simply frustrating, lacking part of the informal social interaction and face-to-face contact of traditional classroom training'. This has been pointed out by some college lecturers who refused to use SM, citing them as disruptive. Another major concern is privacy issues, when platforms like FB are considered, which store an individual's details forever.

Because electronic learning platforms are free and can be used at liberty, they require self-discipline and more responsibility from students, which might be a challenge considering the type of students enrolled at FET colleges. Most of the students have social, economic and behavioural difficulties (SEBD).

\section{Knowledge portals in higher education}

Portal applications offer institutions a planned means of increasing their competitive advantage by encouraging innovation and research activities, which might lead to a greater success rate in grant acquisition, as well as growth in terms of prestige (Rajalakshmi \& WahidiBanu 2009). According to Nonaka and Takeuchi (1995), knowledge creation comprises the utilisation of existing knowledge that is new to a group (tacit) or to an individual. The process becomes comprehensive when the collected knowledge is stored and can be retrieved in future for use by a group or an individual. A KP in this case offers the best option in capturing, sharing and transferring the knowledge; the knowledge acquired is of limited value if not captured, stored and shared. The ultimate goal for the organisation will be knowledge retention, which a KP offers.

\section{Research methodology}

The research unfolded as a dual process. Action research was used in both phases. The first phase investigated how the use of FB could improve the quality and quantity of passes for core subjects. Two NC(V) classes with 45 students doing Computer Programming $(\mathrm{CP})$ as a subject were used for the research. FB was used to contact the students doing $\mathrm{CP}$ outside normal teaching time. Lecturers created two FB groups and invited students randomly to use the platform. The one group used FB with lecturer facilitation and they formed the control group (Group A), whilst the other group (Group B) used FB without lecturer facilitation.

The second phase of this study focused on improving lecturer efficiency through the quality of assessments and the study or lecturer notes prepared by former and current lecturers, approved by the programme manager based on the assessment guideline document. Before the implementation of SM and the $\mathrm{KP}$, students struggled during the final examinations owing to the lack of exposure to subject experts outside the college. This phase aimed to assess whether or not the application of the KP would assist in improving the performance of students. The sample assessments which lecturers used from the KP would assist in boosting the students' year mark and prepare them for the final summative examination. The KP was made public so that all lecturers could use it. They only needed to create an account and register on the local intranet server which hosted the portal. Further, a check on academic efficiency (if any) needed to be tabled and explanations given on whether the pass rates were in relation to portal usage or non-usage.

The subject moderators, in most cases post level two lecturers, would score each lecturer for moderation of the papers. A high score is regarded as full compliance to quality, which is necessary for the students to prepare for their summative tests. The KP served as a central location or repository of resource materials needed by each subject lecturer in respective subject areas. The moderation result, classified according to Department of Education grading, is shown in Table 1.

At the end of the year, the results of the lecturers who used the KP portal were compared to those who did not use the portal; thus, those of 2011 and preceding years. The intent was to use these scores as a baseline to measure variation (either positive or negative) after the implementation of the KP.

The portal prototype was adapted and extended to cater for lecturer interaction whilst on campus. Lecturer interaction was however limited to the campus, although they could access the portal offline. Availability of the KP offline meant that lecturers could familiarise themselves with the set of questions that the students could expect at the end of the year and the expected answers. Also, lecturers could streamline the study material to ensure that the material offered a good match to the national examinations at the end of the year. The KP would be updated on a regular basis to ensure that new trends in the IT sector were addressed. Rau, Gao and Wu (2008) found that students were motivated and enthusiastic to learn once they managed to master assessments set on the KP.

\section{Implementation}

The researchers intended to collect data from 45 students, but seven students dropped out of college along the way. Eventually, 38 questionnaire responses were collected. Data was also collected from the seven lecturers on their use of the KP. Descriptive statistics was used in the form of frequencies, averages and percentages to illustrate the results from the collected data.

Data collection for the research was twofold:

1. Responses from questionnaires distributed to students using SM: Two NC(V) level three classes were used for this study. The combined classes were given a baseline test before the introduction of SM. At a later stage, students were randomly split into two separate (virtual) classes for the purpose of this study. One group (Group A) used SM with lecturer facilitation; the other group

TABLE 1: Department of Education moderation gradings.

\begin{tabular}{ll}
\hline Category & Scores (\%) \\
\hline Strongly valid & $90-100$ \\
Valid & $80-89$ \\
Acceptable & $70-79$ \\
Average & $60-69$ \\
Sub-standard & Below 60 \\
\hline
\end{tabular}


(Group B) did not have lecturer facilitation. This random split was done to avoid possible bias. A FB group was created for use by Group A, whilst Group B studied with use of SM but without lecturer monitoring. This study aimed to determine how the increase in contact time through SM would assist the students in improving their performance. At the end of the term, a questionnaire was distributed to the remaining 38 students, and an analysis was done. Also, test scores for the subject were compared for the two groups.

2. Responses from lecturers and those students who used the KP: The KP used for the research was designed using open source software (PHP, MySQL and CSS) and hosted on the college's internal web server after seeking permission from the campus manager/principal. Lecturers were able to access it from any computer laboratory at the college and in their offices. All lecturers from the IT Department were asked to familiarise themselves with the portal and the information collected which was used for their assessment moderation. The results obtained from the moderation exercise were compared to those before the use of the KP.

\section{Findings \\ Increase in contact time}

From Group A (with FB use), 83\% $(n=15)$ indicated that FB helped to increase their contact time. Group B had six respondents who shared the same sentiments, which is $67.7 \%$ of the total number of respondents (the combined group). From the two groups it could be observed that the students generally agreed that FB could be useful for increasing contact time with the learning material, their peers, and the lecturers or subject experts.

\section{Role of FB in learning computer programming}

In Group $\mathrm{A}, 94.4 \%(\mathrm{~A}=11$; $\mathrm{SA}=6$; totalling 17 students $)$ of the students stated that SM could be used to study CP. In Group B, 23\% $(n=3)$ of the students were of the opinion that FB could be used to study CP, whilst $69.2 \%(n=9)$ of the students from this group were neutral on SM usage in this regard. From these findings it is clear that more students, even those who did not use SM, agreed on the potential of SM to increase the contact time needed for practical subjects like CP. Ten students (55.6\%) indicated that SM had positively changed their attitude towards studying $\mathrm{CP}$ and seven (38.9\%) stated that FB increased their involvement towards studying the subject. Lesser percentages were obtained from Group B, namely 23.1\% $(n=4)$ and 15.4\% $(n$ $=3$ ) respectively. More importantly, the number of students who were satisfied by the responses they received on the FB platform, $67 \%(n=12)$, was significant when compared to the $15.4 \%(n=2)$ from Group B, with $53.8 \%$ offering a neutral response, and $30.8 \%(n=4)$ stating that the responses from their fellow students were not satisfactory, nor reliable.

It is important to note here that the research was conducted in two phases. The one phase attempted to determine whether or not the use of a SM application would improve the contact time necessary for increasing performance, whilst the second phase concentrated on the quality of assessments within the $\mathrm{NC}(\mathrm{V})$ component of the Department of ICT at the FET college. All seven lecturers teaching ICT subjects used the KP for their assessments. Assessment quality is currently reflected 'as a moderation percentage obtained after the subject moderator has scrutinised both lecturer and student portfolios of evidence' (Dietrich et al. 2011). Table 2 represents the moderation scores supplied by the respondents for each of the listed subjects before the application of the KP.

The KP prototype was launched after the first term moderation. All staff members were introduced to the KP and a training session was conducted during a staff development meeting. All lecturers were encouraged to comment freely through email as they interacted with the portal. For the lecturers, the portal included samples of lesson plans and explained how each lesson outcome is achieved when planning. Typical formative assessments included on the KP could be used by both lecturers and students to assess the content. The portal also provided a central store from which lecturers could access important subject content.

Table 3 illustrates average moderation scores for each of the subjects after three rounds of moderation.

It is clear from the results of the survey that the participants of the study had a positive experience with the KP prototype. Table 4 further highlights the positive variation of moderation scores achieved after the introduction of the portal.

As the results show, almost all the subjects, except Hardware and Software, showed an improvement in moderation results. However, it must be noted that even though Electronics showed an improvement of $+/-10 \%$, this is still regarded as below expected or outside the Valid Assessment range. The expected/valid assessment should score an average of between $80 \%$ and $89 \%$ during moderation. Introduction to Systems Development and Data Communication achieved average scores of above $90 \%$.

Apart from initial technical difficulties experienced during the first phase roll-out of the portal, there were few challenges of any significance. This is partly due to the fact that interaction was at first restricted mainly to lecturers to determine whether or not it would affect the validity of their assessment instruments. However, when interaction

TABLE 2: The moderation scores before the knowledge portal introduction.

\begin{tabular}{ll}
\hline Category & Scores (\%) \\
\hline Introduction to Information Systems & $70-79$ \\
Introduction to Systems Development & $70-79$ \\
Electronics & $60-69$ \\
Systems Analysis L3 & $60-69$ \\
Hardware and Software & $80-89$ \\
Principles of Computer Programming & $70-79$ \\
Systems Analysis L4 & $70-79$ \\
Computer Programming & $70-79$ \\
Data Communication and Networking & $80-89$
\end{tabular}


TABLE 3: The moderation scores after the knowledge portal introduction.

\begin{tabular}{|c|c|c|c|c|c|}
\hline Moderation scores & $0 \%-59 \%$ & $60 \%-69 \%$ & $70 \%-79 \%$ & $80 \%-89 \%$ & $90 \%-100 \%$ \\
\hline Introduction to Information Systems & - & - & - & $\mathrm{x}$ & - \\
\hline Introduction to Systems Development & - & - & - & - & $\mathrm{x}$ \\
\hline Electronics & - & - & $x$ & - & - \\
\hline Systems Analysis level 3 & - & - & - & $\mathrm{x}$ & - \\
\hline Hardware and Software & - & - & - & $\mathrm{x}$ & - \\
\hline Principles of Computer Programming & - & - & - & $x$ & - \\
\hline Systems Analysis level 4 & - & - & - & $\mathrm{x}$ & - \\
\hline Computer Programming & - & - & - & $\mathrm{x}$ & - \\
\hline Data Communication and Networking & - & - & - & - & $x$ \\
\hline
\end{tabular}

TABLE 4: The comparison of the moderation scores before and after the knowledge portal introduction.

\begin{tabular}{|c|c|c|c|c|c|c|c|c|c|c|}
\hline \multirow[t]{2}{*}{ Moderation scores } & \multicolumn{5}{|c|}{ Before knowledge portal introduction } & \multicolumn{5}{|c|}{ After knowledge portal introduction } \\
\hline & $0 \%-59 \%$ & $60 \%-69 \%$ & $70 \%-79 \%$ & $80 \%-89 \%$ & $90 \%-100 \%$ & $0 \%-59 \%$ & $60 \%-69 \%$ & $70 \%-79 \%$ & $80 \%-89 \%$ & $90 \%-100 \%$ \\
\hline Introduction to Information Systems & - & - & $x$ & - & - & - & - & - & $\mathrm{x}$ & - \\
\hline Introduction to Systems Development & - & - & $x$ & - & - & - & - & - & - & $x$ \\
\hline Electronics & - & $x$ & - & - & - & - & - & $x$ & - & - \\
\hline Systems Analysis level 3 & - & $x$ & - & - & - & - & - & - & $\mathrm{x}$ & - \\
\hline Hardware and Software & - & - & - & $x$ & - & - & - & - & $\mathrm{x}$ & - \\
\hline Principles of Computer Programming & - & - & $x$ & - & - & - & - & - & $x$ & - \\
\hline Systems Analysis level 4 & - & - & $x$ & - & - & - & - & - & $\mathrm{x}$ & - \\
\hline Computer Programming & - & - & $x$ & - & - & - & - & - & $\mathrm{x}$ & - \\
\hline Data Communication and Networking & - & - & - & $x$ & - & - & - & - & - & $x$ \\
\hline
\end{tabular}

was extended to include students, some problems (mainly involving IT infrastructure) occurred that were not as easy to avoid. Bandwidth was the biggest challenge, which the IT support technicians said was as a result of abuse by some students. There was also an increase in network activity as most students realised the importance of the KP. The other challenge which had to be addressed was access everywhere on the campus, apart from the computer laboratories. Despite these factors, there was a remarkable improvement in the throughput rate from six students graduating in 2011 to 18 students in 2012.

\section{Conclusion}

The research confirms and expands on previous research (Dietrich et al. 2011; Koles \& Nagy 2012; Dzvapatsva 2013; Rau et al. 2008) on the potential of electronic platforms (SM and KP) to increase the performance of FET learners in South Africa. As stated by Gikas and Grand (2013), educators need to make use of emerging technology to teach the so-called Net Generation of students. In fact, Rosmalab and Rosmalab (2012) show that using diverse SM tools together to perform various tasks is more likely to increase individual knowledge acquisition. Learning through electronic platforms like SM and a KP indicates that valuable learning relies not only on social relations and association, but also on personal expression and information aggregation. Having seen the potential of $\mathrm{SM}$ and a $\mathrm{KP}$, it should be emphasised that policies on these platforms need to be followed to obtain the best results from students, as they can be a problem if not well monitored (Cantoni et al. 2004:336).

This article assists in providing a glimpse into the countless ways in which electronic platforms might be used to provide the support needed for collaboration, networking and information sharing within FET institutions. Furthermore, this research will contribute towards a better understanding of how electronic platforms (i.e. SM and a KP) can be used in FET colleges in South Africa. This research confirms that the created KP was valuable not only as a knowledge repository, but also to support other processes. These processes include administrative issues and team building amongst staff members. The researchers hope that future research on the topic will build on, extend, test and complement the results which have been presented in this article.

\section{Limitations of the study}

The research only focused on FB, without comparing it to other mediums. However, the data collected provides a good platform for future research as it shows the current trends in learning and teaching.

\section{Final thoughts}

Consistent with social media trends in general, ICT educators have a responsibility towards themselves (i.e. continuing professional development, joint research, academic or scholarly communication, publishing and producing peer reviewed articles), their students (improving their pass rates and empowering them to have more control over their own education), and the general public. Although SM and other electronic learning platforms offer opportunities, there is an increased need for training on how to use these technologies to improve and augment teaching and learning to support FET students and lecturers, with the ultimate objective of improving pass rates. However, if there are no clear policies on usage, the platforms can be abused by students. 


\section{Acknowledgements Competing interests}

The authors declare that they have no financial or personal relationship(s) that may have inappropriately influenced them in writing this article.

\section{Authors' contributions}

G.P.D. (University of the Western Cape) and A.J.D. (University of the Western Cape) conducted the research and drafted the article, whilst Z.M. (University of the Western Cape) mentored and contributed significantly to the finalisation of the article.

\section{References}

Bock, G.W. \& Kim, Y.G., 2002, 'Breaking the myths of rewards: An exploratory study of attitudes about knowledge sharing', Information Resource Management Journal 15(2), 14-21. http://dx.doi.org/10.4018/irmj.2002040102

Barczyk, C.C. \& Duncan, D.G., 2011, 'Social networking media as a tool for teaching business administration courses', International Journal of Humanities and Social Science 1(17)

Cantoni, V., Cellario, M. \& Porta, M., 2004, 'Perspectives and challenges in e-learning: Towards natural interaction paradigms', Journal of Visual Languages and Computing 15, 333-345. http://dx.doi.org/10.1016/j.jvlc.2003.10.002

Daft, R.L. \& Lengel, R.H., 1986, 'Organizational information requirements, media richness and structural design', Management Science 32(5), 554-571. http:// dx.doi.org/10.1287/mnsc.32.5.554

Dzvapatsva, G.P., 2013, 'The use of social media as a means of improving the quantity and quality of the pass rate in computer programming at FET colleges in the Western Cape', Masters dissertation, University of the Western Cape.

Dietrich, A., Whyte, G. \& Mitrovic, Z., 2011, 'E-learning at FET colleges: The application of a knowledge portal within the ICT Department of the College of Cape Town The ResNes Conference 2011, East London, South Africa.
Ebner, M., Lienhardt, C., Rohs, M. \& Meyer, I., 2010, 'Microblogs in Higher Education - A chance to facilitate informal and process-oriented learning?', Computers \& Education 55(1), 92-100. http://dx.doi.org/10.1016/j.compedu.2009.12.006

Hamid, S., Chang, S. \& Kurnia, S., 2009, 'Identifying the use of online social networking in higher education', ASCILITE 2009 conference, December 2009, pp. 6-9.

Kabilan, K.M., Ahmad, N. \& Abidin, M.J.Z., 2010, 'Facebook: An online environment for learning of English in institutions of higher education?' Internet and Higher Education 13, 179-187. http://dx.doi.org/10.1016/j.iheduc.2010.07.003

Kaplan, A.M. \& Haenlein, M., 2010, 'Users of the world, unite! The challenges and opportunities of social media', Business Horizons 53(1), 59-68. http://dx.doi. org/10.1016/j.bushor.2009.09.003

Kietzmann, J.H., Hermkens, K., McCarthy, I.P. \& Silvestre, B.S., 2011, 'Social media? Get serious! Understanding the functional building blocks of social media', Business Horizons 54, 241-251. http://dx.doi.org/10.1016/j.bushor.2011.01.005

Koles, B. \& Nagy, P., 2012, 'Facebook usage patterns and school attitudes', Multicultural Education \& Technology Journal 6(1), 4-17. http://dx.doi. org/10.1108/17504971211216283

Gikas, J. \& Grant, M.M., 2013, 'Mobile computing devices in higher education: Student perspectives on learning with cellphones, smart phones and social media', Internet and Higher Education 19, 18-26.

Leung, C.F., 2002, 'Promoting an active learning environment within a congested curriculum', International Conference on Engineering Education Proceedings, Manchester, United Kingdom.

Nonaka, I. \& Takeuchi, H., 1995, The knowledge-creating company, Oxford University Press, New York.

Rajalakshmi, S. \& WahidiBanu, D., 2009, 'Developing an education web portal for knowledge sharing and capturing', International Journal of Engineering and Technology 1(3). http://dx.doi.org/10.7763/IJET.2009.v1.43

Rau, P.P., Gao, Q. \& Wu, L., 2008, 'Using mobile communication technology in high school education: Motivation, pressure, and learning performance', Computers \& Education 50, 1-22. http://dx.doi.org/10.1016/j.compedu.2006.03.008

Rosmalab, F. \& Rosmalab, D., 2012, 'Study of social networking usage in higher education environment', 3rd International Conference on e-Learning ICEL 2011 23-24 November 2011, Bandung, Indonesia, Procedia - Social and Behavioral Sciences 67, 156-166.

Sarachan, J. \& Reinson, K.F., 2011, 'Public issues, private concerns: Social media and course management systems in higher education', Cutting-edge Technologies in Higher Education 1, 227-244. http://dx.doi.org/10.1108/S20449968(2011)0000001014

Short, J.W., Williams, E.E. \& Christie, B., 1976, The social psychology of telecommunications, John Wiley, London. 